\title{
Cultivating Graduate STEM Pathways: How Alliance-Based STEM Enrichment Programs Broker Opportunity for Students of Color
}

\author{
Ariana L. Garcia ${ }^{1}$, Tonisha B. Lane ${ }^{2}$ and Blanca E. Rincón ${ }^{1 *}$ \\ ${ }^{1}$ Department of Educational Psychology and Higher Education, University of Nevada Las Vegas, Las Vegas, NV, United States, \\ ${ }^{2}$ School of Education, Virginia Tech, Blacksburg, VA, United States
}

To understand how higher education institutions broker graduate opportunities for Students of Color (SOCs) in STEM, we employ a single case study of a Louis Stokes Alliance for Minority Participation (LSAMP) alliance. Drawing primarily from student interviews and informed by Small's (2006) organizational brokerage theory, our findings illuminate how 1) alliance-based STEM enrichment programs (SEPS) bridge social capital via interorganizational networks and 2) how SEP instability creates barriers to building the trust that is central to the brokerage process. We conclude with recommendations for future research and practice.

Keywords: social capital, educational enrichment programs, graduate education, students of color, STEM-science technology engineering mathematics

\section{INTRODUCTION}

Though Communities of Color (i.e., Blacks/African Americans, Hispanics/Latina/o/x, Native Americans) comprise approximately $33 \%$ of the U.S. population (U.S. Census Bureau, 2019), they only made up $12 \%$ of the graduate student population in STEM in 2019 (National Science Foundation, National Center for Science and Engineering Statistics, 2019). While a number of factors influence this disparity in the number of Students of Color (SOCs) in graduate STEM programs relative to their representation in the United States, research shows that students who have extensive social networks are more likely to attend graduate school (Martin, 2009). Still, we know very little about how SOCs acquire and leverage their social capital to access graduate education. Lin (1999) defines social capital as the "resources embedded in a social structure which are accessed and/or mobilized in purposive actions" ( $p .35)$. Central to this definition are three elements that facilitate social reproduction: accessibility, embeddedness, and use. Social capital posits that an individual has access to resources (e.g., information, influence, social credentials) that are embedded in their social network and relationships. The ability to mobilize social capital to garner other forms of capital (e.g., economic, cultural, human) is constrained by the size and quality of the social networks available to the individual. While much of the existing literature illuminates the importance of social capital in students' transitions from high school to college (Perna and Titus, 2005; Pérez and McDonough, 2008; Rios-Aguilar and Deil-Amen, 2012), very little attention is given to post-graduate transitions. Additionally, much of the existing research on social capital and graduate education focuses on students in graduate school (Ovink and Veazey, 2011; Espino, 2014), not those seeking to access graduate school. 
For students transitioning from college to graduate study, social capital may include having undergraduate research experiences, recommendations (preferably those written by faculty members), and pedigree (Posselt, 2016). These are sources of capital that SOCs, who have been historically underserved in higher education, may not have equal access to due to a lack of opportunity and limited resources. For example, McCoy et al. (2017) uncovered that SOCs have disparate experiences with faculty across institutional contexts. At predominantly White institutions (PWIs), SOCs may encounter challenges with identifying and accessing supportive mentors compared to their counterparts at historically Black colleges and universities (HBCUs) (McCoy et al., 2017). Consequently, SOCs may have to utilize other institutional agents to attain the support necessary to realize their graduate school goals. STEM enrichment programs (SEPs) that aim to broaden minority participation in STEM have served a critical role in addressing this need.

Research shows that SEPs have been instrumental in supporting SOCs to attain the social capital necessary to access graduate education. Lane's (2015) study of a Louis Stokes Alliance for Minority Participation (LSAMP) program uncovered that the connections students made and the opportunities afforded to them in SEPs influenced their graduate school aspirations. Research on the Meyerhoff Scholars program at the University of Maryland, Baltimore County found that SOCs who participated in their SEP were nearly five times more likely to attend graduate school and complete a Ph.D. in STEM (Maton et al., 2016). Their multipronged services and family-like atmosphere are some of the program features that facilitated critical social networks for participants (Maton et al., 2016). Access to undergraduate research experiences, supportive faculty, and relationships with peers with similar interests, provided through SEPs, are some of the driving forces extending SOCs' pathways toward graduate education (Lane, 2015; Lane, 2016).

Despite the importance of SEPs for promoting interest in graduate education, we still know little about how they broker social capital for SOCs in STEM. Thus, the purpose of this study was to understand how an alliance-based STEM enrichment program brokers social capital that facilitates entry into graduate education for SOCs. This study contributes to an emerging strand of research that offers an organizational perspective on social capital development and use. Further, this study offers important insights into increasing the participation and success of SOCs in STEM graduate education programs and careers.

\section{LITERATURE REVIEW}

Considering that SOCs are underrepresented in STEM graduate education, scholars have attempted to understand factors that support graduate enrollment. This theme comprises the first part of this literature review. Then, we review relevant literature on how educational opportunity is brokered by higher education.
More specifically, we explore who brokers social capital, what resources are brokered and how, and to what end.

\section{Graduate Pathways for Science Technology Engineering Mathematics Students of Color}

While Black and Latina/o/x STEM students are more likely to aspire to obtain graduate or professional degrees than White students, they are less likely to enroll in graduate and professional education (Eagan et al., 2013). Several scholars have examined the factors that thwart graduate pathways (Malcom and Dowd, 2012; McCoy et al., 2017). Malcom and Dowd (2012) studied the role of undergraduate debt in graduate school enrollment for STEM students. They found that both typical and heavy debt borrowing can hinder graduate enrollment for all STEM students; however, for Latina/o/x students, there was a negative effect of "heavy borrowing" on graduate school enrollment. African American students were the most likely to be heavy borrowers; yet, there was no significant effect on their graduate enrollment. Another factor inhibiting graduate participation is how SOCs perceive the STEM environment (McCoy et al., 2017; Castellanos, 2018). For example, when Latinas in STEM perceived the classroom environment as hostile, they were less inclined to pursue a STEM career or graduate education (Casetellanos, 2018). Additionally, for SOCs in STEM, faculty and institutional contexts could play a role in whether students felt encouraged or "weeded out" of STEM (McCoy et al., 2017). At a PWI, SOCs felt that faculty were gatekeepers to resources such as internships and research opportunities that would promote STEM careers and educational pathways. In comparison, students at an HBCU found that faculty created opportunities for them and provided assistance with career guidance or graduate school preparation.

In studying factors that promote SOCs' decisions to pursue a graduate STEM degree, scholars have found that participating in undergraduate research has a strong influence on igniting and sustaining student's aspirations to pursue a graduate or professional degree in STEM (Strayhorn, 2010; Eagan et al., 2013; Russell et al., 2018). STEM students who participated in undergraduate research reported stronger faculty support than students who did not have similar opportunities (Eagan et al., 2013). Moreover, students who had meaningful research experiences (e.g., collected data, analyzed data) had higher levels of graduate school aspirations compared to students who were less involved in the research process (Strayhorn, 2010). Other factors that facilitate graduate enrollment are scholarships and graduate preparatory programs (Myers and Pavel, 2011; MacPhee et al., 2013). A longitudinal study of the Gates Millennium Scholarship Program, a scholarship program for underrepresented minorities that provides funding for students pursuing STEM graduate degrees, found that scholarship recipients were $41 \%$ more likely to enroll in a graduate program and $61 \%$ more likely to be enrolled in a STEM graduate program than non-program participants (Myers and Pavel, 2011). Similarly, MacPhee et al. (2013) examined STEM students in a McNair Scholars Program, a U.S. Department of Education Program aimed at preparing underrepresented minorities for doctoral studies. This study 
found that participation in the McNair Scholars Program increased students' self-efficacy and academic performance, which predicted a greater likelihood of applying to graduate or professional school.

\section{Social Capital and Students of Color in Higher Education}

Researchers have found that social capital is often brokered through individuals and educational enrichment programs within higher education. Institutional agents-individuals who occupy high-status positions in an institution (Stanton-Salazar, 2011)_serve as "bridges" (Museus and Neville, 2012) that broker important social capital for students within higher education. Faculty and staff have been found to act as bridges' that connect students to resources within their social networks (DeilAmen, 2011; Museus and Neville, 2012; Dika and Martin, 2018). For example, Deil-Amen (2011) found that faculty were key in brokering social capital and academic integration for Latina/o/x engineering students. Hurtado et al. (2008) found that STEM students who developed relationships with faculty were more likely to participate in undergraduate research. Peers were also important brokers of social capital (Hurtado et al., 2008; Rincón et al., 2020). For Black students specifically, advice from upperclass students predicted research participation. In addition to individuals, educational enrichment programs have also been found to broker social capital for SOCs (Stolle-McAllister, 2011; Winkle-Wagner and McCoy, 2016; Lane and Id-Deen, 2020), specifically STEM bridge programs (Ovink and Veazey, 2011; Stolle-McAllister, 2011; Lane and Id-Deen, 2020). Graduate school preparatory programs also increased social capital by cultivating student-faculty interactions and creating a network of peer support (Winkle-Wagner and McCoy, 2016).

Institutional agents and educational enrichment programs broker important educational resources that expand educational opportunities for SOCs. Educators (i.e., professors, college personnel, K-12 teachers) act as bridges to internships, research experiences, graduate school opportunities, and scholarships (Dika and Martin, 2018). Martin et al. (2013) found that Latinas in engineering utilized institutional services such as advising and support programs that provided them with crucial information to progress in their major. Additionally, a STEM bridge program brokered peer relationships that led to family-like bonds and social capital for Black college women and high school girls that supported their career aspirations (Lane and Id-Deen, 2020). Similarly, a biology bridge program provided educational services and physical spaces that increased social capital by fostering connections that were instrumental for getting into graduate school or a post-college job (Ovink and Veazey, 2011).

In addition to the types of resources brokered, faculty, and administrators utilized different methods to broker resources for students. Deil-Amen (2011) found that faculty brokered resources such as academic integration and information related to scholarships, academics, and major-related information both in and outside of class. Faculty and upperlevel administrators also brokered resources by applying for large grants to create programming or services for SOCs that enhanced their social capital (Garcia and Ramirez, 2018). Furthermore, institutional structures can also have a role in brokering social capital. For example, Beattie and Thiele (2016) found that smaller class sizes facilitate the brokering of social capital by increasing student interaction with faculty and peers. Regardless of the method, interpersonal trust was key for whether students utilized the resources provided by institutional agents (Torres et al., 2006; Museus and Neville, 2012; Ream et al., 2014). Torres et al. (2006) found that Latina/o/x students do not automatically trust authority figures. For many students, shared experiences allowed them to pursue and develop trusting relationships with institutional agents that then allowed them to access important social capital (Museus and Neville, 2012).

Accessing social capital embedded within social networks provides multiple educational benefits for SOCs (Rios-Aguilar and Deil-Amen, 2012; Tovar, 2015; Schwartz et al., 2018). While research has primarily focused on how accumulating social capital supports students' transitions from high school to college (Perna and Titus, 2005; Pérez and McDonough, 2008; Rios-Aguilar and Deil-Amen, 2012), researchers also found that acquiring social capital supports college student outcomes. For example, social capital has been found to impact student GPAs and STEM persistence (Ovink and Veazey, 2011; Tovar, 2015; Schwartz et al., 2018). Resources related to social capital such as meeting an instructor outside of class and participating in a college support program were found to increase Latina/o/x community college students' GPAs and intentions to persist to degree completion (Tovar, 2015). Additionally, McCallen and Johnson (2020) surveyed first-generation college students and measured social capital through their quality of interactions with campus actors (i.e., students, academic advisors, faculty, student services, and administrative staff) and found that greater frequency of faculty interaction and higher numbers of sources of social capital were positively correlated with GPA.

In summary, much attention has been paid to how institutional agents (individuals) act as bridges to important sources of social capital by broadening students' networks and resources embedded within these networks that help students navigate postsecondary institutions (Stanton-Salazar, 2011; Museus and Neville, 2012). Increasingly, researchers are also capturing the important role of educational enrichment programs in extending students' social capital (StolleMcAllister, 2011; Winkle-Wagner and McCoy, 2016; Lane and Id-Deen, 2020). However, much of this research is focused on individual programs (Stolle-McAllister, 2011; Winkle-Wagner and McCoy, 2016; Lane and Id-Deen, 2020) and the types of social capital garnered through participation in STEM enrichment programs (Ovink and Veazey, 2011; Lane and IdDeen, 2020) without attending to how higher education institutions, via SEPS, tie students to other institutions and partners through interorganizational networks or how this social capital supports graduate school aspirations. To this end, this study extends the literature in two important ways: 1) it explores the process of brokering graduate school-related resources through alliance-based STEM enrichment programs that aim to broaden participation in STEM as well as the forms of 
resources brokered; and 2) it helps us better understand how social capital facilitates the college to graduate school transition. It does this by exploring two interrelated research questions: What graduate school-related resources are brokered by alliance-based STEM Enrichment Programs? How do alliance-based STEM Enrichment Programs broker graduate opportunities?

\section{CONCEPTUAL FRAMEWORK}

For this study, we draw on Lin's (1999) network theory of social capital. In the context of graduate education, social capital can facilitate access to graduate school knowledge, goods, and services that can be exchanged for graduate admissions and enrollment (human capital). Accordingly, one could invest in expanding their networks to garner greater and "higher" quality resources not currently available in existing networks. Extending the example above, an individual could participate in a webinar to learn about (and potentially from) others who have applied to and attended graduate school to increase one's chances of graduate school admission.

Indeed, much of the social capital literature has focused on this very phenomenon of how individuals develop social ties-relationships between individuals-that bridge entry into new networks and assumedly provide access to better resources (Lin, 1999). Small (2006) extends this concept of bridging capital through social ties to the study of individual-organizational ties. That is, how organizations themselves broker resources to individuals by providing access to resources embedded within interorganizational networks. To theorize organizational resource brokerage, Small (2006) studied how childcare centers function as resource brokers for low-income parents. By connecting parents to nonprofit and government agencies, childcare centers transferred information, services, and goods embedded within their interorganizational networks to parents utilizing childcare services. According to Small (2006), interorganizational brokerage was dually facilitated by the degree to which a resource was actively and formally brokered. As an example of both formal and active resource brokering, childcare center staff offered referral services to connect parents with goods and services provided through partner organizations. Importantly, Small (2006) argues that the effectiveness with which resource brokerage occurs is shaped by organizational efficiencies; that is, the extent to which a resource is formalized within an organization (stability), the organization's ability to persist amidst external pressures (resilience), and its ability to build trusting relationships to enable the brokering of sensitive resources (capacity).

Extending Small's (2006) organizational brokerage theory to education, Duncheon and Relles (2019) found this framework useful for understanding how educational institutions become important resource brokers for college-bound, first-generation youth at an urban high school. As such, we apply Small's (2006) organizational brokerage theory to the study of higher education institutions that are members of an alliance within the Louis Stokes Alliance for Minority Participation to understand how interorganizational networks, in this case those facilitated through an alliance-based STEM enrichment program, transmit capital to individuals, in this case, SOCs in STEM.

\section{METHODOLOGY}

To understand how social capital is embedded and transmitted to individuals via organizational resource brokers, we employ a single case study of a Louis Stokes Alliance for Minority Participation (LSAMP) alliance, a federally funded multiinstitution alliance focused on racially diversifying STEM fields. As an SEP that facilitates interorganizational collaborations, this LSAMP alliance serves as an instrumental case of interorganizational resource brokerage and meets all of Small's (2006) characteristics of an organizational broker. First, by design, the LSAMP alliance interacts and partners with other organizations; it is made up of loosely coupled campus-based LSAMP programs and non-LSAMP partners that share divergent and collective interests (e.g., preparing students for graduate school), is subject to external pressures (e.g., federal funders), and has physical space at alliance institutions that become sites for student interaction.

Founded in the early 2000s, this LSAMP alliance comprises six postsecondary four-year institutions located in the Northeastern part of the United States. This alliance includes three public, landgrant, flagship universities, and three urban private institutions. This cross-institutional partnership shares a common goal of increasing the number of underrepresented racially and ethnically minoritized students (i.e., Black, Latina/o/x, Pacific Islander, and Native American) matriculating into, and successfully completing, high-quality undergraduate degrees in STEM. As a senior alliance that has successfully received several cycles of funding through the National Science Foundation (NSF), this LSAMP alliance is focused on increasing the number of racially and ethnically minoritized students pursuing graduate degrees in STEM. In addition to crossinstitutional partnerships, this LSAMP alliance has also established strategic partnerships with non-alliance programs that facilitate entry into graduate school, including the National Graduate Degrees for Minorities in Engineering and Science (GEM) Consortium, Research Experience for Undergraduates (REU), McNair Scholars, other LSAMP alliances, and international partner universities, among others (Table 1). LSAMP participants have access to a wide range of goods and services, including but not limited to academic bridge programs, first-year experiences, networking events, peer mentoring, undergraduate research funding, research symposiums, and study abroad opportunities.

\section{Data Sources}

This qualitative case study draws on a variety of data sources gathered from a larger longitudinal research project initiated in 2016 with funding from the NSF. The data sources that informed this case study include student interviews, informal interviews with program coordinators, and document analysis. Interviews with students regarding their participation in LSAMP were the primary data source. These interviews were conducted with the 
TABLE 1 | Interorganizational LSAMP networks.

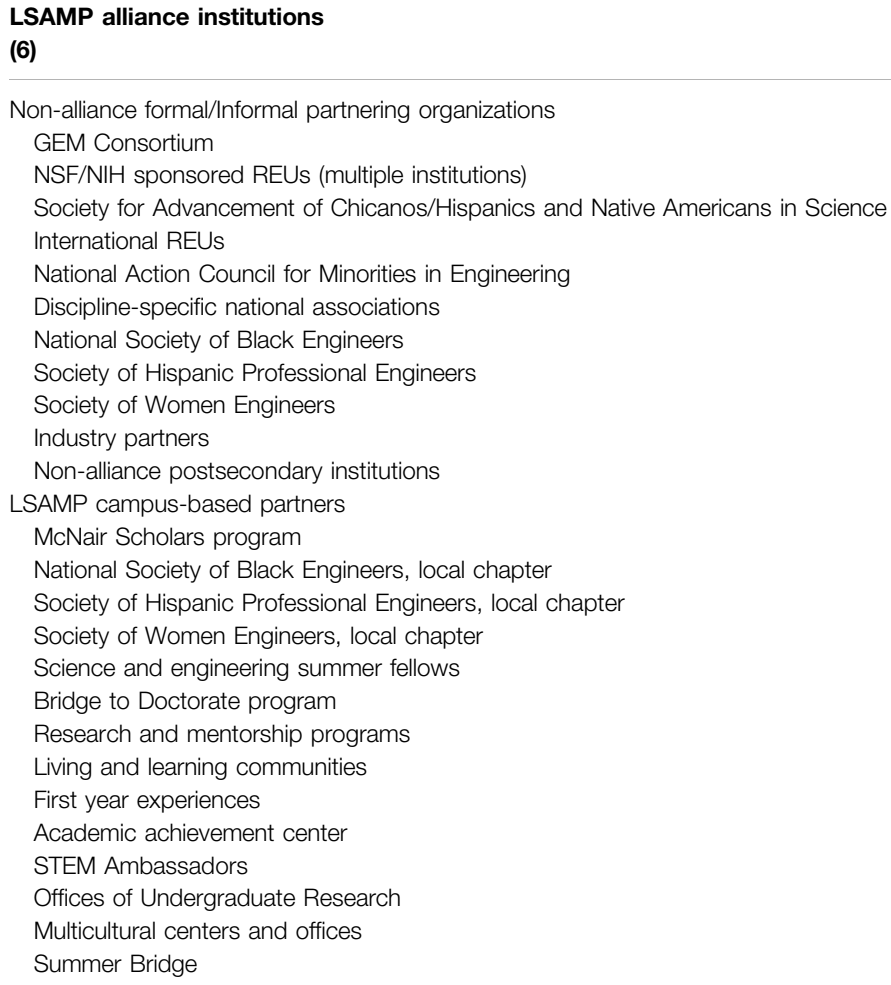

LSAMP cohort that began their academic studies in 2016. Because one institution was a new member to the LSAMP alliance and did not have a cohort of students in the Fall 2016 semester, only five of the six alliance institutions took part in this study. Members of the research team conducted 30 one-on-one semi-structured interviews with students in the spring 2017 semester when students were in the second year of their academic studies. Research team members then collected 20 follow-up interviews during the spring semester of the students' fourth year in college (2020; Table 2 for demographic information). While all students who took part in the first round of interviews were invited to participate in follow-up interviews, only 20 agreed. Approximately 3-10 students were interviewed at each institution (Table 3). Data were collected in person or via telephone and were audio recorded with the consent of participants. The interviews ranged between approximately 40 and $80 \mathrm{~min}$ in length. These semi-structured interviews included questions about students' involvement in LSAMP and how their participation in LSAMP shaped their educational and career trajectories. For example, students were asked about their involvements on and off campus that facilitated their educational and career goals, and how those involvements came to be (Table 4 for sample interview questions). Informal interviews with LSAMP staff and administrators were also conducted to better understand the nature of the campusbased programs, including where the programs were organizationally situated within the university, the supports and services they provided to students, and how they worked with other partners on and off campus. Finally, program documents including evaluation and annual reports were collected and reviewed.

\section{Data Analysis}

To analyze our data, members of the research team transcribed each audio recording and reviewed each transcript for accuracy. Then, we de-identified the transcripts by replacing students' names and other identifying information with pseudonyms. Next, we uploaded the transcripts to Dedoose, an online software used for conducting analysis of qualitative data. To begin the coding process, members of the research team worked collaboratively to develop a codebook. This step helped ensure a shared understanding of the codes that guided our analysis. Anchoring our data analysis was Small's (2006) framework of organizational resource brokerage. As an analytical tool, this framework informed the development of deductive codes that captured the types of resources students described accessing through their participation in LSAMP (e.g., information, goods, and services). We also created a series of process codes reflecting how these resources were brokered via the LSAMP alliance (e.g., passive/active and formal/informal transmission). For an overview of our coding scheme, please see Table 5.

Once these initial codes were established, two members of the research team carefully read and analyzed a subset of the interview transcripts using an interpretive approach (Denzin and Lincoln, 2008). We then came together to identify similarities and differences in our coding of these interview 
TABLE 2 | First-year student profile of 2016-2021 LSAMP alliance cohort $(n=30)$.

\begin{tabular}{|c|c|c|c|}
\hline Pseudonym & Gender & Race/Ethnicity & Initial major \\
\hline Abigail $^{\mathrm{a}}$ & Woman & Black & Engineering \\
\hline $\mathrm{Ada}^{\mathrm{a}}$ & Woman & Black & Engineering \\
\hline Aliyah & Woman & Black & Biology and health sciences \\
\hline Andre & Man & Black & Engineering ${ }^{b}$ \\
\hline Angel & Man & Latinx & Engineering \\
\hline Angela & Woman & Black & Biology and health sciences \\
\hline Antonio $^{a}$ & Man & Latinx & Biology and health sciences ${ }^{b}$ \\
\hline Awilda $^{a}$ & Woman & Black/Latinx & Biology and health sciences \\
\hline Daniel & Man & Latinx & Physical sciences \\
\hline David & Man & Black/Latinx & Engineering \\
\hline Devan & Man & Black & Engineering \\
\hline Doris & Woman & Black & Biology and health sciences ${ }^{b}$ \\
\hline Emilio $^{a}$ & Man & Latinx & Engineering ${ }^{b}$ \\
\hline Erica & Woman & Latinx & Biology and health sciences \\
\hline $\mathrm{Jada}^{\mathrm{a}}$ & Woman & Black & Accounting \\
\hline Jamal & Man & Black & Engineering \\
\hline Jazmine $^{a}$ & Woman & Latin $x$ & Engineering \\
\hline Jordan & Woman & Latinx/White & Engineering \\
\hline Joshua & Man & Black/Latinx & Biology and health sciences \\
\hline Josie & Woman & Latinx/White & Engineering \\
\hline Juana $^{a}$ & Woman & Latinx & Biology and health sciences \\
\hline Keisha & Woman & Black/White & Engineering \\
\hline Lorenzo $^{a}$ & Man & Latin $x$ & Engineering \\
\hline Luisana & Woman & Latinx & Engineering \\
\hline Marco & Man & Latinx White & Biology and health sciences ${ }^{b}$ \\
\hline Marisela & Woman & Black/Latinx & Engineering \\
\hline Marquis & Man & Black & Digital media and design \\
\hline Ofiong $^{a}$ & Woman & Black & Engineering \\
\hline Ricardo & Man & Latinx & Engineering \\
\hline Xavier & Man & Black/White & Physical sciences \\
\hline
\end{tabular}

${ }^{a}$ Denotes first-generation.

${ }^{b}$ Denotes transfer student.

transcripts until discrepancies were resolved and a greater shared understanding of the codes was established. When coding discrepancies were encountered, the third author stepped in and served as a peer-debriefer (Saldaña, 2018). This step strengthened the codes and increased the credibility of our findings (Saldaña, 2018). In the second round of analysis, one member of the research team individually coded the remaining transcripts. During this process, we also engaged in axial coding which sought to uncover relationships and patterns across participants' responses. This led us to identify the themes discussed in our findings.

Because we are a multi-member team, continuous peer debriefing and the use of analytic memos capturing "emergent patterns, categories and subcategories, themes, and concepts" (Saldaña, 2018, p. 44) served as critical components in our analytical process. Specifically, the team used analytic memos (Saldaña, 2018) to help identify patterns and themes cutting across the LSAMP alliance. These memos included researcher notes and reactions, institutional profiles, and information about the types of resources brokered through LSAMP and non-alliance partners and the mechanisms through which the resources were brokered.

\section{Research Positionality}

Race, culture, and prior life experiences impact the positionality of researchers and thus are important to discuss (Milner, 2007). This research study was conducted by Women of Color: two Latina women, and one Black woman. All three are researchers who broadly study the experiences of marginalized groups in STEM. Two authors are assistant professors of higher education, and one is a doctoral student studying higher education. As undergraduate students, we all participated in educational enrichment programs that sought to broaden minority participation in higher education. Additionally, one professor was a former administrator of an SEP program at a large public PWI. Collectively, our backgrounds as Women of Color who have navigated higher education and educational enrichment programs gave us unique insight into the participants'

TABLE 3 | Students interviewed by institution and type.

\begin{tabular}{|c|c|c|c|}
\hline Institution & $\begin{array}{c}\text { Number of students } \\
\text { interview } 1\end{array}$ & $\begin{array}{c}\text { Number of students } \\
\text { interview } 2\end{array}$ & Institutional size \\
\hline A & 10 & 6 & Large \\
\hline$B$ & 6 & 5 & Large \\
\hline C & 5 & 3 & Medium \\
\hline $\mathrm{D}$ & 6 & 4 & Large \\
\hline $\mathrm{F}$ & 3 & 2 & Large \\
\hline
\end{tabular}

TABLE 4 | Sample interview questions.

1. Tell me about your current educational goals

2. Can you tell me about any experiences that you've had since you've started college that have reinforced your decisions to pursue an undergraduate degree in ?

3. Tell me about your current career goals

4. What informed your decision to go directly into graduate/professional school/workforce?

5. Tell me about your involvement in LSAMP.

6. What has been most valuable about your participation in LSAMP?

7. How does your involvement in LSAMP relate to your educational/career goals?

8. Where/who do you go to when you need advice about your future in STEM (graduate school, careers in STEM, etc.)? 
TABLE 5 | Sample coding scheme.

\begin{tabular}{|c|c|c|c|}
\hline Code & Code type & Description & Example \\
\hline Resources Brokered_Information & Descriptive & Information provided by LSAMP & LSAMP provided funding for student participation in a conference \\
\hline Mechanisms_Informal & Process & Informal ways resources are brokered by LSAMP & Meeting LSAMP peers and sharing information \\
\hline Mechanisms_Formal & Process & Formal ways resources are brokered & LSAMP sent an email about an REU experience \\
\hline
\end{tabular}

experience and the program's structure. We drew on our experiences throughout the research process, thus informing our data collection and analysis.

\section{FINDINGS}

Two interrelated themes emerged from our analysis of the data. First, we found that LSAMP alliance institutions brokered social capital for SOCs in STEM by exerting influence on key educational processes and facilitating the flow of graduate school-related information that enabled the accumulation of educational resources (i.e., goods and services) to promote student aspirations and entry into graduate school. These resources were garnered through campus-based LSAMP programs, across the LSAMP alliance, and through partnering organizations. Second, students' abilities to both acquire and mobilize their social capital was predicated on the trust built between students and LSAMP staff.

\section{Brokering Science Technology Engineering Mathematics Graduate Opportunities Influence}

LSAMP students benefited from the authority of LSAMP staff both within and outside LSAMP alliance institutions. The influence exerted by LSAMP staff helped students access and retain important educational resources that supported their persistence in STEM. Students described how LSAMP staff bridged access to educational opportunities that they otherwise would not have access to. Ada, an engineering student, explained how the LSAMP director connected her to various opportunities. She reflected,

He has definitely been able to help others I know connect with people in grad schools and just being able to network with the people that he knows. I know that I was interested in going to the (University) and he was like, "Okay, I'm gonna call my contact over there and see if I can set you up with somebody who is on the graduate academic board or something like that," or "I'm gonna see if I can connect you with somebody who does the type of research that you want to do and see if you can have a conversation with them."

Acting as bridges and writing letters of recommendation were the primary ways that LSAMP staff exerted their influence and extended their social capital on behalf of students. Through recommendations, staff tied students to other higher education institutions and partnering organizations. These letters of recommendation were important for securing research opportunities and graduate admissions.

\section{Information}

LSAMP also facilitated students' access to important information about graduate school. For example, the LSAMP alliance hosts the National GEM Consortium Getting Ready for Advanced Degrees Laboratory (GEM GRAD Lab) each year. The GEM GRAD Lab is an interactive conference for underrepresented undergraduate students that raises awareness about what graduate school is, how to prepare for it, and funding opportunities. It also provides networking opportunities with GEM graduate fellows. In essence, the LSAMP alliance's hosting of the GEM GRAD Lab was a way of transferring resources from the GEM Consortium to the alliance's students. Students often attended the GEM GRAD Lab early on during their undergraduate work, which was key for cultivating graduate school aspirations early on. Angel, an engineering student, attended the GEM GRAD Lab during his first year in college. He reflected,

\section{My friend and I were going to it. And we were like, why} are we going to this? It's a graduate program. And we're barely through school. And then once we left, we were like, wow. That's actually really eye-opening. So that was my first exposure to really thinking about-I always viewed grad school as completely unaffordable. But then once you see all the funding that's out there, it makes it seem more achievable and attainable.

For Angel and his peers, the LSAMP alliance brokered informational resources that helped him learn about various options for funding graduate education. This information was "eye-opening" and expanded his educational options early on in his undergraduate career.

Some LSAMP programs also introduced students to information about undergraduate research and how to get involved in various educational opportunities that set them on graduate pathways. It was often through formal mechanisms such as first-year experiences, emails, and bridge programs that this crucial information was shared. Other students accessed information about research opportunities directly through advising from their LSAMP coordinator. For Xavier, a physical science major, LSAMP served as a bridge to an undergraduate research opportunity via referral. He explained, 
So, during my freshman year I went to my advisor at LSAMP, and I was just telling him about some of the research that I was interested in, and he pointed me in the direction of the (Research Lab). So what I did was I emailed someone that worked in the (Research Lab)And yeah, we just went from there. I went to a meeting, and they got me set up to work within the (Research Lab).

For Xavier, and many other students, LSAMP introduced them to information regarding undergraduate research and served as a bridge to beginning high-impact educational experiences that were crucial for entry into STEM graduate programs. These included undergraduate research opportunities at the host institution, across the alliance, and at non-alliance institutions.

LSAMP also helped students navigate the graduate school application and decision-making process. Joshua, a biology and health science major, explained that he had multiple graduate school offers and was unsure how to make a decision. He spoke highly of his time in LSAMP and the community he gained through his participation, and he thus turned to the LSAMP director, Tina, for advice about how to select a graduate program. Tina taught him how to ask graduate programs about resources for SOCs, much like LSAMP. Joshua explained, "So, I made sure to ask that wherever I went. Some schools are a lot better at answering it than others. So I'm going to ask the question." Tina provided Joshua with valuable information about how to determine if a graduate program would be a good fit and what resources it had for SOCs.

Information was also brokered through informal mechanisms. Campus-based LSAMP programs provided a physical gathering space for students to connect and form relationships with other SOCs in STEM. Many students formed deep friendships with fellow LSAMP students where additional information was brokered. For example, Doris, a biology and health science major, described how her LSAMP peers shared graduate school-related information:

I just found out that you can actually-there's a way you can apply for a fee assistance program to apply to medical school. I think ... the point of networking is really just learning about resources you wouldn't otherwise know about from a bunch of your friends.

From friendships she cultivated through LSAMP, she accessed information that would facilitate her entry into medical school.

\section{Goods}

Beyond facilitating information sharing, LSAMP served as a resource broker for goods that facilitated graduate opportunities. Through the LSAMP alliance, students had access to funding opportunities to conduct research abroad through International Partnerships. These international research experiences equipped students with valuable skills and expanded their worldview. Joshua, a biology and health science major, explained, "(T)he program paid for us to do immersion trips every weekend. Every weekend we're traveling somewhere else around China to do things." LSAMP helped remove financial burdens and opened doors to new opportunities. For Keisha, an engineering student who struggled with connecting to engineering and to her university, her international research experience connected her to the field and supported her persistence in STEM. She reflected,

I was able to get money through the research internship that I've done, and then, sometimes, if we're doing research on campus Dean (Anderson) can pay us through the LSAMP funding. So, the funding has just been super helpful. Because that's funding that I don't get anywhere else.

The funding LSAMP provided was key for many students in gaining the research experience necessary for entry into graduate school. Through these research experiences, students gained valuable skills to add to their resumes, developed relationships with faculty, and enhanced their graduate school aspirations.

The funding from LSAMP came in many different forms. At some universities, students had access to book scholarships when they participated in LSAMP events. For others, the funding was brokered passively through association with LSAMP. Joshua explained, "Because I'm in LSAMP, that waived the (graduate) application fee for every university except for Harvard, which was amazing." Joshua's participation in LSAMP brokered goods that directly supported his entry into graduate school. Antonio, a biology and health science student, discussed the many funding opportunities related to graduate school that LSAMP brokered:

I've still got a GRE book. You know, I've got these free waivers for me to take the GRE. (...) In LSAMP, the benefits are ... what (David) can help you out with. Like he can give you a GRE book. He could help you out, get some waivers and could give you advice and help you out to go to study abroad or help you get your paper presented at (Institution A).

The various funding opportunities that were available through LSAMP, and in association with LSAMP, helped broker graduate opportunities for students.

\section{Services}

LSAMP served as a bridge to connect students to other graduate school-related services. For many students, LSAMP connected them to other SEPs and institutional services that were vital in brokering graduate opportunities. Ricardo, an engineering student, explained how LSAMP served as a bridge to the McNair Scholars program, where he received a faculty mentor, was exposed to graduate programs, and gained access to services that helped prepare him for graduate school. He reflected,

And through LSAMP I really learned a lot about opportunities, to be honest. I actually did the McNair fellows last May and that pushed me to apply to be a McNair Scholar, and I'm currently a McNair Scholar. So 
definitely LSAMP has exposed me to different opportunities, particularly looking into research and graduate school, because that's really like the push for LSAMP, and I guess what McNair pushes for.

It was through his participation in an LSAMP-sponsored firstyear experience (FYE) that Ricardo and peers were introduced to the McNair Scholars program and he was able to access additional formal services related to graduate school.

Other students accessed valuable services related to graduate school through the annual LSAMP symposium. Students explained that by attending this annual symposium with the LSAMP alliance, they had the opportunity to present their research, network with STEM students across alliance institutions, and learn more about graduate school. For David, an engineering student, this annual symposium strengthened his graduate school aspirations. He reflected,

(B)efore I thought I could, you know, go to school, just get my master's, like, do the B.S./M.S. program, but not even do the B.S./M.S. program, just get my bachelor's, and be done with it and go into the workforce. But then because of the first poster symposium I went to, I switched to the B.S./M.S. program, and then the next one that I got to I, yeah, I got some more information about the Ph.D., and I keep going to them, I learn more and more about, you know, getting my Ph.D.

For David, and many other students, their participation in their campus-based LSAMP program served as a bridge to the resources embedded within the LSAMP alliance. This annual symposium had a critical influence on many students' perceptions of graduate school. According to an internal annual LSAMP report, a total of 29 students attended the symposium and were surveyed afterwards. Of those surveyed, $55 \%$ planned to apply for graduate school, $10 \%$ had already applied, and $3 \%$ had already been accepted into a graduate program. The majority of the students who attended the LSAMP alliance symposium had graduate school aspirations. This is consistent with interview data in which many students shared how this symposium initiated or reinforced their aspirations to attend graduate school.

\section{Efficiency of Brokering Resources}

Our findings also revealed that trust was key to accessing resources embedded within LSAMP interorganizational networks. Many participants had strong relationships with LSAMP staff that allowed them to seek graduate school-related advice and become connected to important educational resources that ignited and sustained their graduate school aspirations. Interrelated with trust was how LSAMP instability shaped students' abilities to leverage resources embedded within the LSAMP alliance. For LSAMP students attending institutions with high staff turnover or organizational change, their inability to build trusting relationships with LSAMP staff impacted their ability to both acquire and mobilize their social capital.

\section{Cultivating Institutional Trust}

Many LSAMP staff earned students' trust by demonstrating care for both students' well-being and their educational success. Marco, a biology and health science major, explained, " $(\mathrm{T})$ he connection came from just knowing that he was really concerned with me as an individual succeeding at this institution. Having that moral support allowed me to have trust in David and hear what he had to say." Many students expressed similar sentiments. For Joshua, trust began with a shared experience and was cultivated over time. Joshua described how LSAMP provided him a sense of community that helped build trust and access the resources provided. Joshua reflected,

(T)his was the first time I saw other people that looked like me, when I joined LSAMP. And that was a big thing for me, where I hated feeling different. And now I was in with other people where I didn't feel different.

Joshua's involvement with LSAMP was influential in providing him a community with other Students of Color and Scholars of Color. This helped Joshua develop a strong relationship with the LSAMP director, Tina. He shared, "She was also one of the few Black PhDs that I knew at (Institution D)." Their shared racial identity helped him trust Tina and turn to her for advice. He reflected,

It just helped me a lot to open up and to talk with her because ... It always felt like she was just always very genuine. She treated me like I was one of her kids. It was nice to have that loving figure in a new place where I didn't really look like other people.

Their common background helped serve as the foundation for trust that allowed Joshua to access many helpful resources related to graduate school.

Trust also shaped who students turned to when seeking various forms of support. For many students, LSAMP was a space they trusted more than institutional resources available to all students. Angela, a biology and health sciences student explained, "I know I could use other resources on campus, like the Career Development Center or similar services. But I guess since I had a more personal relationship with David, he could give me more personalized advice." Angela knew there were university resources available to help with her resume and cover letters; however, she trusted David and had built a personal relationship with him that influenced her decision to turn to him, rather than the career center.

\section{Louis Stokes Alliance for Minority Participation (In)Stability and Resource Brokerage}

While many students found LSAMP to be a place they trusted for support and resources, there were also students who were unsure of LSAMP's role and their involvement in the program. Some campus-based LSAMP programs experienced high staff turnover and organizational instability. For example, most of the students interviewed at Institution $\mathrm{C}$ had participated in a 
pre-orientation program sponsored by LSAMP; however, most were unaware of what it meant to participate in LSAMP beyond the pre-orientation program. Aliyah, a biology and health science student, was unsure how she became connected with LSAMP. She reflected,

So, I think the reason why I was part of LSAMP was because of the (Office of Multicultural Affairs), because I know that they do work with LSAMP closely? I'm not $100 \%$ sure of the whole process and everything. And I want to say (pre-orientation program) is also part of it, but I could be wrong. I think that's why I'm more involved in it. (...) I'm not 100 percent sure, because it's been like, rerouting everywhere.

Aliyah's reflections were consistent with how students at Institution C perceived LSAMP. Many students explained how the restructuring and staff turnover contributed to their lack of involvement. Similarly, Luisana, an engineering student, was initially involved in LSAMP; however, due to organizational restructuring, her involvement never progressed past the preorientation program. She explained,

I applied, and then they never got back to me. I applied, and you're supposed to get interviewed. And then I didn't get interviewed. I just got an email like, I'm sorry. You weren't accepted-They've gone through two changes recently at the Office of Multicultural Affairs, so it's been shaky.

The organizational instability within Institution C's LSAMP program created confusion and a lack of understanding regarding students' involvement in LSAMP and the resources LSAMP could provide. However, LSAMP institutions that had strong organizational ties and that were connected with offices that had a similar mission were able to increase trust and serve as bridges to graduate school-related resources.

\section{DISCUSSION}

Findings from this study reveal that SOCs in STEM benefit from passive and active transmission of social capital facilitated through LSAMP alliance institutions and their interorganizational network. Extending Small's (2006) framework to the study of higher education institutions sheds light on how colleges and universities broker graduate opportunities through making resources embedded in interorganizational networks accessible to individuals. This framework proved useful for examining how the LSAMP alliance actively and formally brokered resources for SOCs in STEM seeking to access graduate school. For example, we uncovered how LSAMP alliance institutions utilized their interorganizational network to broker graduate school-related resources such as graduate school application fee waivers and access to graduate school-related workshops. This framework also highlighted a myriad of ways LSAMP enables SOCs to develop and accumulate social networks that are critical to identifying resources, information, and individuals who can help them navigate the graduate school application process and eventual admission into graduate education. The more we know about how SEPs broker social capital for SOCs, the more we can systemize and formalize these processes to make them more efficient and likely to result in greater success for SOCs in STEM undergraduate programs. In line with Small's (2006) organizational brokerage theory, the ability to cultivate institutional-individual trust became foundational for brokering social capital. To that end, students were more likely to inquire about graduate school-related issues with LSAMP administrators than with administrators and faculty outside of LSAMP. However, we learned that the instability of some LSAMP programs threatened to fracture this trust, and ultimately to impede access to important graduate school-related resources.

LSAMP participants were also able to establish informal networks with students and institutional agents who were instrumental in accessing graduate school information and other forms of social capital. Formal and informal networks afforded through LSAMP and its interorganizational networks enabled SOCs to extend their networks and obtain resources that were not readily available to them outside of their program affiliation (Lin, 1999; Small, 2006). Program participants bridged relationships and connections to fortify a seamless pathway to graduate school (Dika and Martin, 2018). As such, participants easily accessed program leaders and fellow students to get information and resources and used these networks to tap into other networks for support. Their affiliation with LSAMP also enabled them to acquire goods and services necessary to meet their graduate school aspirations. For example, LSAMP administrators facilitated opportunities for students to formally join $\mathrm{McNair}$ programs, or informally attend graduate schoolrelated workshops sponsored by McNair. In these ways, connecting students to resources, people, and information promoted formal and informal transmission of capital.

Our data also revealed that passive forms of capital transmission are just as important as more active forms. Doris, for example, learned through an informal interaction with a peer student that there was a fee assistance program for medical school. These types of chance interactions are afforded through participation in programs like LSAMP (Lane, 2015; Maton et al., 2016). Even mundane, taken-for-granted knowledge can have a resounding impact on one's pathway toward post-graduate education. Thus, program leaders should continue to create structured and formal opportunities for students to build relationships and community with one another in order to facilitate informal transference of capital.

Signature events such as the GEM GRAD Lab allowed program leaders to provide information about pathways to graduate school (e.g., application process, funding) early in students' undergraduate careers. Sanders and Landrum (2012) discovered that students in their senior year of college knew relatively little about the graduate admissions process. They concluded that approaches to preparing undergraduate students for the graduate admissions process are insufficient. 
In contrast, our study showed that GEM's early exposure to graduate school-related knowledge fostered participants' aspirations and made them better prepared to apply for and transition into graduate school when the time came. Strategies such as these contribute to a smoother transition into graduate school for LSAMP students compared to students who may not have access to this information early in their college career, if ever. These types of systematic advantages afforded through LSAMP are critical to groups that have been historically disenfranchised in graduate education. For example, Ramirez (2011) interviewed 24 Latina/o/x doctoral students who indicated that "no one taught (them) the steps" for accessing graduate school (p. 204). "Because (graduate) education is the gateway to research careers and the professoriate," campus leaders cannot leave learning about graduate school to chance if we are to broaden participation in the academy (Ramirez, 2011, p. 205). Likewise, as Sanders and Landrum (2012) illustrate, it cannot be assumed that other institutional actors and units will disseminate information about graduate pathways.

LSAMP students also benefited from bridging multiple programs and high-impact practices, including McNair, GEM GRAD Lab, research abroad, and other undergraduate research experiences. In the literature, high-impact practices, also known as HIPs, are in-depth learning experiences that require substantial time and dedication from students and faculty involved in them (Kuh, 2008). Students who engage in HIPs perform better academically, have higher rates of degree completion, have stronger critical thinking skills, and tend to value challenging and stimulating cognitive experiences (Kuh, 2008; Finley and McNair, 2013; Kilgo et al., 2015; Kuh et al., 2017). Not only are these outcomes beneficial for enriching a student's undergraduate career but engaging in HIPs can make students more competitive for graduate school (Strayhorn, 2010; Eagan et al., 2013). There is also some evidence that HIPs are more meaningful for underrepresented students (Finley and McNair, 2013), although they tend to participate in them at a lower rate than their majority counterparts (Kuh et al., 2017). This may be due to systemic and structural inequities in some institutional contexts that create roadblocks for SOCs and their capacity to access HIPs (Patton et al., 2015). Some of these stem from faculty who fail to engage students in undergraduate research or support their access to internships, thus limiting opportunities to transmit disciplinespecific knowledge (McCoy et al., 2017). As such, serving as a conduit for HIPs demonstrates another way that SEPs broker opportunities that are crucial to graduate pathways.

LSAMP aided students in brokering material goods such as funding for research abroad that enhanced students' credentials and cultural capital, contributing to favorable outcomes in the graduate admissions process. Additionally, students reported receiving fee waivers for graduate school applications. The cost to apply to graduate school can create unique barriers for students. Application fees, standardized tests, and costs associated with graduate school visits can all be deterrents to applying to graduate school, especially for students who are considering graduate school amid substantial undergraduate debt (Malcom and Dowd, 2012). The resources provided through LSAMP lessens these burdens, increasing the likelihood that students will be well-positioned to apply. The value of these forms of cultural and economic capital cannot be overstated; further study into how SEPs mitigate financial barriers to graduate STEM pathways is warranted.

This study points to trust as a critical factor in SOCs seeking out and being receptive to advice and support for accessing graduate education. Students valued the connection and sense of community gained through LSAMP. Consequently, they were more likely to engage program leaders when trying to understand pathways to graduate school. Other researchers have pointed out the significance of institutional agents who develop trusting relationships among SOCs in educational contexts as a precursor to addressing their needs (DeilAmen, 2011; Museus and Neville, 2012; Dika and Martin, 2018). This finding is also consistent with the finding from Ream et al. (2014) that trust may matter more to STEM SOCs than to their White counterparts, especially relative to their motivation and career expectations. Our study confirms previous research concerning the criticality of trusting relationships in the process of brokering resources and information for graduate STEM pathways. One manner in which trust is earned is through "solidarity and shared meaning in the context of institutional realities" (StantonSalazar, 2011, p. 1088). SOCs, in the current study, reported feeling more at ease when obtaining information because they recognized programs leaders had their best interest in mind. Program leaders, some of whom were People of Color with STEM graduate degrees, uniquely understood the context in which the students were navigating graduate pathways. This shared solidarity and identity also played a role in building trusting relationships. Our data also revealed that students were more likely to inquire about and accept help from LSAMP administrators than they were from staff in the general university. This finding speaks to the need for and relevance of STEM enrichment programs as well as why they should be sustained on college campuses. The personal relationships SEP administrators foster with students are guided by an ethic of care and strategies found in otherparenting (i.e., wherein institutional agents take on culturally relevant, parent-like behaviors) (Lane, 2015; Lane and Id-Deen, 2020). Studies show that caring and otherparenting approaches advanced within these programs are responsible for retaining many SOCs in STEM (Lane, 2015; Lane, 2016; Lane and Id-Deen, 2020). On the other hand, our study also uncovered that instability in these programs may impede trusting relationships between administrators and students.

Participants in our study noted the impact of staff turnover and how it created unstable SEP environments. There are a myriad of factors that influence the stability of SEPs. One is the cost of running them (Watford, 2007; Koenig, 2009). If federal funds are not available, such as the case with LSAMP, these programs may cease to exist. Many colleges and universities may not have the resources or desire to sustain these programs without external funding sources (Rincón and GeorgeJackson, 2016). Staff also tends to be limited (Shehab et al., 2012). If a staff person receives a promotion or departs the institution, these units can become understaffed. 
Consequently, access to graduate school-related resources embedded within these interorganizational networks can be easily jeopardized.

\section{IMPLICATIONS}

The findings from this study offer important implications for future research and practice. One area ripe for further inquiry relates to how program instability coincides with a student's ability to build trusting relationships with SEP staff, thus impacting an SEP's ability to transmit social capital. Future research could examine how different organizational contexts shape the efficiency of brokering social capital, examining, for example, how SEPs are funded, where SEPs are situated organizationally within an institution, and how the stability of an SEP is likely to impact its ability to broker educational opportunities. Further, future research could investigate how SEPs broker other important student outcomes beyond pursuing graduate education opportunities. For example, we know that SOCs are able to develop important social networks in STEM while in college, but less is known about how they mobilize and maintain these networks to garner educational and career opportunities post-graduation.

The findings from this study position LSAMP programs as exemplary models for other educational programs looking to support SOCs in STEM. Central to LSAMP's success is the intentional partnership among diverse postsecondary institutions that comprise the alliance, campus-based partners, and non-alliance partners. In particular, the LSAMP alliance demystifies the graduate plan of study by "spelling out" the formula for student success, thus offering seamless transitions to graduate school for SOCs. Students are provided early exposure to educational information that makes graduate opportunities known and attainable for SOCs, educational goods and services that provide students with educational exposure, opportunities that provide a competitive edge when

\section{REFERENCES}

Beattie, I. R., and Thiele, M. (2016). Connecting in Class?: College Class Size and Inequality in Academic Social Capital. J. Higher Edu. 87 (3), 332-362. doi:10.1353/jhe.2016.0017

Castellanos, M. (2018). Examining Latinas' STEM Career Decision-Making Process: A Psychosociocultural Approach. J. Higher Edu. 89 (4), 527-552. doi:10.1080/00221546.2018.1435133

Deil-Amen, R. (2011). Socio-academic Integrative Moments: Rethinking Academic and Social Integration Among Two-Year College Students in Career-Related Programs. J. Higher Edu. 82 (1), 54-91. doi:10.1353/jhe.2011.0006

Denzin, N. K., and Lincoln, Y. S. (2008). Strategies of Qualitative Inquiry. 3rd ed. Thousand Oaks, CA: Sage.

Dika, S. L., and Martin, J. P. (2018). Bridge to Persistence: Interactions with Educators as Social Capital for Latina/o Engineering Majors. J. Hispanic Higher Edu. 17 (3), 202-215. doi:10.1177/1538192717720264

Duncheon, J. C., and Relles, S. R. (2019). Brokering College Opportunity for FirstGeneration Youth: The Role of the Urban High School. Am. Educ. Res. J. 56 (1), 146-177. doi:10.3102/0002831218788335 applying to graduate school, and formal and informal networks that support the cultivation of important networks of peers who have similar backgrounds and aspirations. Moreover, SEPs are successful at bridging students' access to educational resources because they do so in culturally responsive ways. That is, SEPs recognize the importance of fostering relationships with students in order to counter the historical mistrust between SOCs and postsecondary institutions, especially PWIs.

\section{DATA AVAILABILITY STATEMENT}

The raw data supporting the conclusions of this article will be made available by the authors upon request.

\section{ETHICS STATEMENT}

The studies involving human participants were reviewed and approved by IRB, UNLV. The participants provided their written informed consent to participate in this study.

\section{AUTHOR CONTRIBUTIONS}

AG, TL, BR contributed equally to this work. All authors contributed to the first draft of the paper and took the lead on the different sections. All authors contributed to manuscript revision, read, and approved the submitted version.

\section{FUNDING}

This work was funded by the National Science Foundation (Award: 1619629). Any opinions, findings, and conclusions expressed in this article are those of the authors and do not necessarily reflect the views of the NSF.

Eagan, M. K., Hurtado, S., Chang, M. J., Garcia, G. A., Herrera, F. A., and Garibay, J. C. (2013). Making a Difference in Science Education: The Impact of Undergraduate Research Programs. Am. Educ. Res. J. 50 (4), 683-713. doi:10.3102/0002831213482038

Espino, M. M. (2014). Exploring the Role of Community Cultural Wealth in Graduate School Access and Persistence for Mexican American PhDs. Am. J. Edu. 120 (4), 545-574. doi:10.1086/676911

Finley, A., and McNair, T. (2013). Assessing Underserved Students Engagement in High-Impact Practices. Available at: https://www.aacu. org/assessinghips

Garcia, G. A., and Ramirez, J. J. (2018). Institutional Agents at a Hispanic Serving Institution: Using Social Capital to Empower Students. Urban Edu. 53 (3), 355-381. doi:10.1177/0042085915623341

Hurtado, S., Eagan, M. K., Cabrera, N. L., Lin, M. H., Park, J., and Lopez, M. (2008). Training Future Scientists: Predicting First-Year Minority Student Participation in Health Science Research. Res. High Educ. 49 (2), 126-152. doi:10.1007/ s11162-007-9068-1

Kilgo, C. A., Ezell Sheets, J. K., and Pascarella, E. T. (2015). The Link between HighImpact Practices and Student Learning: Some Longitudinal Evidence. High Educ. 69 (4), 509-525. doi:10.1007/s10734-014-9788-Z 
Koenig, R. (2009). U.S. Higher Education. Minority Retention Rates in Science Are Sore Spot for Most Universities. Science 324, 1386-1387. doi:10.1126/ science.324_1386a

Kuh, G. D. (2008). High-impact Educational Practices: What They Are, Who Has Access to Them and Why They Matter. Washington, DC: Association of American Colleges and Universities.

Kuh, G., O’Donnell, K., and Schneider, C. G. (2017). HIPs at Ten. Change Mag. Higher Learn. 49 (5), 8-16. doi:10.1080/00091383.2017.1366805

Lane, T. B., and Id-Deen, L. (2020). Nurturing the Capital within: A Qualitative Investigation of Black Women and Girls in STEM Summer Programs. Urban Edu., 004208592092622. doi:10.1177/0042085920926225

Lane, T. B. (2016). Research Environments as Counterspaces? Examining Spaces that Inhibit and Support Science Identity Development for Black Students in STEM. Urban Edu. Res. Pol. Annuals 4 (1), 160-169.

Lane, T. B. (2015). "It's Not Just One Thing!" Examining the Role of a STEM Enrichment Program in Facilitating College Readiness and Retention Among Underserved Students of Color. Doctoral dissertation, East Lansing, MI: ProQuest. Google Scholar https://Lane_grad.msu_0128D_13827\%20.

Lin, N. (1999). Building a Network Theory of Social Capital. Connections 22 (1), 28-51.

MacPhee, D., Farro, S., and Canetto, S. S. (2013). Academic Self-Efficacy and Performance of Underrepresented STEM Majors: Gender, Ethnic, and Social Class Patterns. Analyses Soc. Issues Public Pol. 13 (1), 347-369. doi:10.1111/ asap. 12033

Malcom, L. E., and Dowd, A. C. (2012). The Impact of Undergraduate Debt on the Graduate School Enrollment of STEM Baccalaureates. Rev. Higher Edu. 35 (2), 265-305. doi:10.1353/rhe.2012.0007

Martin, J. P., Simmons, D. R., and Yu, S. L. (2013). The Role of Social Capital in the Experiences of Hispanic Women Engineering Majors. J. Eng. Educ. 102 (2), 227-243. doi:10.1002/jee.20010

Martin, N. D. (2009). Social Capital, Academic Achievement, and Postgraduation Plans at an Elite, Private university. Sociological Perspect. 52 (2), 185-210. doi:10.1525/sop.2009.52.2.185

Maton, K. I., Beason, T. S., Godsay, S., Sto Domingo, M. R., Bailey, T. C., Sun, S., et al. (2016). Outcomes and Processes in the Meyerhoff Scholars Program: STEM PhD Completion, Sense of Community, Perceived Program Benefit, Science Identity, and Research Self-Efficacy. CBE Life Sci. Educ. 15 (3), ar48. doi:10.1187/cbe.16-01-0062

McCallen, L. S., and Johnson, H. L. (2020). The Role of Institutional Agents in Promoting Higher Education success Among First-Generation College Students at a Public Urban university. J. Divers. Higher Edu. 13 (4), 320-332. doi:10.1037/dhe0000143

McCoy, D. L., Luedke, C. L., and Winkle-Wagner, R. (2017). Encouraged or Weeded Out: Perspectives of Students of Color in the STEM Disciplines on Faculty Interactions. J. Coll. Student Dev. 58 (5), 657-673. doi:10.1353/ csd.2017.0052

Milner, H. R. (2007). Race, Culture, and Researcher Positionality: Working Through Dangers Seen, Unseen, and Unforeseen. Educ. Res. 36 (7), 388-400. doi:10.3102/0013189X07309471

Museus, S. D., and Neville, K. M. (2012). Delineating the Ways that Key Institutional Agents Provide Racial Minority Students with Access to Social Capital in College. J. Coll. Student Dev. 53 (3), 436-452. doi:10.1353/ csd.2012.0042

Myers, C. B., and Pavel, D. M. (2011). Underrepresented Students in STEM: The Transition from Undergraduate to Graduate Programs. J. Divers. Higher Edu. 4 (2), 90-105. doi:10.1037/a0021679

National Science Foundation, National Center for Science and Engineering Statistics (2019). Women, Minorities, and Persons with Disabilities in Science and Engineering: 2019. Alexandria, VA: Special Report NSF 19-304. Available at: https://www.nsf.gov/statistics/wmpd.

Ovink, S. M., and Veazey, B. D. (2011). More Than "Getting Us through:" A Case Study in Cultural Capital Enrichment of Underrepresented Minority Undergraduates. Res. High Educ. 52 (4), 370-394. doi:10.1007/s11162-0109198-8

Patton, L. D., Harper, S. R., and Harris, J. (2015). "Using Critical Race Theory to (Re) Interpret Widely Studied Topics Related to Students in US Higher Education," in Critical Approaches to the Study of Higher Education. Editors
A. M. Martínez-Alemán, B. Pusser, and E. M. Bensimon (Baltimore: Johns Hopkins University Press), 193-219.

Pérez, P. A., and McDonough, P. M. (2008). Understanding Latina and Latino College Choice. J. Hispanic Higher Edu. 7 (3), 249-265. doi:10.1177/ 1538192708317620

Perna, L. W., and Titus, M. A. (2005). The Relationship between Parental Involvement as Social Capital and College Enrollment: An Examination of Racial/ethnic Group Differences. J. Higher Edu. 76 (5), 485-518. doi:10.1353/ jhe.2005.0036

Posselt, J. R. (2016). Inside Graduate Admissions: Merit, Diversity, and Faculty Gatekeeping. Boston: Harvard University Press.

Ramirez, E. (2011). "No One Taught Me the Steps": Latinos' Experiences Applying to Graduate School. J. Latinos Edu. 10 (3), 204-222. doi:10.1080/ 15348431.2011.581105

Ream, R. K., Lewis, J. L., Echeverria, B., and Page, R. N. (2014). Trust Matters: Distinction and Diversity in Undergraduate Science Education. Teach. Coll. Rec. 116 (5).

Rincón, B. E., Fernández, É., and Dueñas, M. C. (2020). Anchoring Comunidad: How First- and Continuing-Generation Latinx Students in STEM Engage Community Cultural Wealth. Int. J. Qual. Stud. Edu. 33, 840-854. doi:10.1080/09518398.2020.1735567

Rincón, B. E., and George-Jackson, C. E. (2016). STEM Intervention Programs: Funding Practices and Challenges. Stud. Higher Edu. 41 (3), 429-444. doi:10.1080/03075079.2014.927845

Rios-Aguilar, C., and Deil-Amen, R. (2012). Beyond Getting in and Fitting in. J. Hispanic Higher Edu. 11 (2), 179-196. doi:10.1177/1538192711435555

Russell, M. L., Escobar, M., Russell, J. A., Robertson, B. K., and Thomas, M. (2018). Promoting Pathways to STEM Careers for Traditionally Underrepresented Graduate Students. Negro Educ. Rev. 69 (1-4), 5-143.

Saldaña, J. (2018). Researcher, Analyze Thyself. Int. J. Qual. Methods 17 (1), 1-7. doi:10.1177/1609406918801717

Sanders, C. E., and Landrum, R. E. (2012). The Graduate School Application Process. Teach. Psychol. 39 (2), 128-132. doi:10.1177/0098628312437697

Schwartz, S. E. O., Kanchewa, S. S., Rhodes, J. E., Gowdy, G., Stark, A. M., Horn, J. P., et al. (2018). "I’m Having a Little Struggle with This, Can You Help Me Out?": Examining Impacts and Processes of a Social Capital Intervention for First-Generation College Students. Am. J. Community Psychol. 61 (1-2), 166-178. doi:10.1002/ajcp.12206

Shehab, R., Murphy, T. J., and Foor, C. E. (2012). "Do They Even Have that Anymore": the Impact of Redesigning a Minority Engineering Program. J. Women Minor. Scien Eng. 18 (3), 235-253. doi:10.1615/ JWomenMinorScienEng.2013002354

Small, M. L. (2006). Neighborhood Institutions as Resource Brokers: Childcare Centers, Interorganizational Ties, and Resource Access Among the Poor. Soc. Probl. 53 (2), 274-292. doi:10.1525/sp.2006.53.2.274

Stanton-Salazar, R. D. (2011). A Social Capital Framework for the Study of Institutional Agents and Their Role in the Empowerment of Low-Status Students and Youth. Youth Soc. 43 (3), 1066-1109. doi:10.1177/ $0044118 X 10382877$

Stolle-McAllister, K. (2011). The Case for Summer Bridge: Building Social and Cultural Capital for Talented Black STEM Students. Sci. Educator 20 (2), 12-22. doi:10.1007/s10956-010-9228-5

Strayhorn, T. L. (2010). Undergraduate Research Participation and STEM Graduate Degree Aspirations Among Students of Color. New Dir. Institutional Res. 2010 (148), 85-93. doi:10.1002/ir.364

Torres, V., Reiser, A., LePeau, L., Davis, L., and Ruder, J. (2006). A Model of FirstGeneration Latino/a College Students' Approach to Seeking Academic Information. NACADA J. 26 (2), 65-70. doi:10.12930/0271-9517-26.2.65

Tovar, E. (2015). The Role of Faculty, Counselors, and Support Programs on Latino/a Community College Students' Success and Intent to Persist. Community Coll. Rev. 43 (1), 46-71. doi:10.1177/0091552114553788

U.S. Census Bureau (2019). American Community Survey. Available at: https:// data.census.gov/cedsci/profile?q=United\%20States\&g=0100000US.

Watford, B. A. (2007). "Undergraduate Student Support Programs," in Women and Minorities in Science, Technology, Engineering, and Mathematics: Upping the Numbers. Editors R. J. Burke and M. C. Mattis (Northhampton, MA: Edward Elgar Publishing, Limited), 276-313. 
Winkle-Wagner, R, and McCoy, D. L. (2016). Entering the (Postgraduate) Field: Underrepresented Students' Acquisition of Cultural and Social Capital in Graduate School Preparation Programs. J. Higher Edu. 87 (2), 178-205. doi:10.1353/jhe.2016.0011

Conflict of Interest: The authors declare that the research was conducted in the absence of any commercial or financial relationships that could be construed as a potential conflict of interest.

Publisher's Note: All claims expressed in this article are solely those of the authors and do not necessarily represent those of their affiliated organizations, or those of the publisher, the editors and the reviewers. Any product that may be evaluated in this article, or claim that may be made by its manufacturer, is not guaranteed or endorsed by the publisher.

Copyright (C) 2021 Garcia, Lane and Rincón. This is an open-access article distributed under the terms of the Creative Commons Attribution License (CC BY). The use, distribution or reproduction in other forums is permitted, provided the original author(s) and the copyright owner(s) are credited and that the original publication in this journal is cited, in accordance with accepted academic practice. No use, distribution or reproduction is permitted which does not comply with these terms. 